\title{
Decoupling and Contextualizing Self-Sacrifice and Intentions to Act for the Benefit of the Environment
}

\author{
Darcy R. Dupuis* \\ University of Guelph
}

Steven Arnocky

Nipissing University

We comment on Liu and Sibley's examination of cross-national differences in the relationship between perceptions of global warming and intentions to make personal sacrifices for the environment. First, although self-sacrifice is not necessary for pro-environmental action, the authors' outcome measure conflates intentions to act and self-sacrifice. In addition to being problematic at the individual level, this framing may result in cross-national differences in meaning. Second, for developed nations, the authors seem to downplay the importance of external factors that can affect behavior. We expand by discussing barriers to action that cannot be surmounted by individuals' intentions alone.

Across 34 nations, Liu and Sibley (2012) found that the perceived importance of climate change predicted willingness to make personal sacrifices for the benefit of the environment, and that this relationship was stronger in nations with a higher Human Development Index (HDI). Two broad issues strike us as particularly worthy of commentary. First, the authors' focus on self-sacrifice may be problematic. Second, the emphasis on the importance of personal intentions may be overstated for high HDI nations and understated for low HDI nations. We build on the authors' discussion by considering external barriers to and facilitators of action that may be considered in conjunction with, rather than separate from, people's intentions.

As environmentally significant behaviors (ESB) can be pursued for numerous reasons, including self-interest, the authors' focus on "willingness to make sacrifices" for the environment may be unnecessarily limiting. It is true that

\footnotetext{
* Correspondence concerning this article should be addressed to Darcy R. Dupuis, Psychology Department, University of Guelph, Guelph, Ontario, Canada N1G 2W1 [e-mail: ddupuis@uoguelph.ca]
} 
pro-environmental behavior can stem from concern for other people, other species, and the planet in general (Arnocky, Stroink, \& DeCicco, 2007; Arnocky \& Stroink, 2011a, 2011b), yet it can also_-often simultaneously_be a product of self-interest (Kaplan, 2000; Bamberg \& Möser, 2007). Research has found, for example, that people can receive benefits such as positive emotions and interpersonal relationships through their responses to climate change (e.g., Maiteny, 2002).

Furthermore, by limiting their dependent measure to include only sacrificial intentions, the authors may have inadvertently placed greater constraints on the responses of people from low versus high HDI nations. Thus, the focus on sacrifice may have been problematic cross-nationally. People of high HDI nations may have substantial leeway to make choices that forego immediate self-interest without necessarily reducing their quality of life (e.g., conserve energy, accept higher prices). People in developing nations, by contrast, may be less capable of foregoing self-interest for the sake of the environment without impacting their quality of life. This problem is touched on briefly by the authors in their discussion, where they struggle with envisioning the kinds of sacrifices people of low HDI countries can make for the environment. How does one accept higher prices for goods and services if one cannot afford higher prices? How does one conserve energy beyond minimal levels of consumption? If the measure of intentions had been more broadly defined-for instance, by including pro-environmental behaviors that are consistent with self-interest-the authors' findings may have revealed a more modest or perhaps insignificant difference in the relationships between importance of global warming and intentions to act in low versus high HDI nations.

Our second concern involves the emphasis placed on intentions. In their discussion, Liu and Sibley appear to conclude that individuals' choices and intentions to act are critical to mitigating greenhouse gas emissions in high but not low HDI nations. By contrast, they emphasize top-down initiatives as important only in low HDI nations. However, intentions alone do not always predict effective behaviors (Bamberg, 2002; Stern, 2000), and should not be decoupled from external influences on pro-environmental choices (Clayton \& Brook, 2005). Instead, intentions may be considered as part of a larger system of top-down policy and bottom-up community-based initiatives. As Liu and Sibley give only cursory attention to the relationship between societal initiatives and individuals' intentions, we highlight some barriers preventing intentions from producing meaningful actions and point to strategies that may help to overcome such barriers.

First, lack of feedback for ESB may be a major barrier to action (Swim et al., 2010). For example, among people who attempt to engage in pro-environmental consumption practices, absence of feedback regarding whether one is actually having a positive impact can be quite burdensome (Connolly \& Prothero, 2008). As climate change is a complex process stemming from collective effects of individuals, communities, and industry, it is largely impossible to observe environmental 
outcomes stemming from individual behavior (Dilling \& Moser, 2007). Benefits of action must therefore be other than observable effects on the climate. Some ways to provide positive feedback include giving visible feedback for energy use, which can effectively emphasize the potential for monetary savings, and framing action as a community undertaking, through which positive interpersonal relationships may be forged (Swim et al., 2010).

Second, although people may often have environmental concerns, devoting attention to and making informed choices in the complex and potentially frightening domain of climate change (see Kazdin, 2009; Swim et al., 2010) may not be a primary concern. Life domains in which choices must be made are extensive and varied in terms of precedence (e.g., finances, food, personal safety), and the issue of climate change tends to rank low on personal lists of national and environmental concerns (Leiserowitz, 2007). How can concerns that are buried under a mountain of more urgent priorities be uncovered? One solution may be to incorporate reminders into the social environment. Research on behavioral prompts (e.g., McKenzie-Mohr, 2000) and recent findings concerning nonconscious goal pursuit (see Aarts, 2007; Bargh, 2006) suggest that well-placed reminders may help to activate pro-environmental goals that are conducive to ESB. Social marketing strategies may be implemented in settings such as supermarkets to remind people to attend to and act upon otherwise neglected pro-environmental goals.

Third, even if pro-environmental intentions are acted on, people may have difficulty engaging in the most critical forms of ESB. For example, although intentions to reduce daily consumption (curtailment behaviors; Gardner \& Stern, 2008) may be pursued with little assistance, more effective one-time efficiency behaviors, such as retrofitting one's home or installing solar panels, demand connections and negotiations between consumers and green product or service providers. Here, numerous social, financial, and institutional barriers must be surmounted. We see promise in grassroots community organizations functioning as orchestrators of these relationships (see Seyfang, Smith, \& Longhurst, 2010; Tang, Karbu, \& Hämäläinen, 2011). Community-based initiatives such as ecomarkets and energy fairs provide citizens with opportunities to engage with local green businesses, thus facilitating consumer behavior that is harmonious with pro-environmental intentions (see Dupuis, Shantz, \& Bergen, 2011).

Liu and Sibley are likely correct in suggesting that a capacity to meet basic needs among individuals in developed countries affords opportunities to act on environmental concerns. However, their conflation of pro-environmental behavior and self-sacrifice for the environment appears to be unnecessarily limiting. Furthermore, rather than considering people in high HDI nations as mainly driven by internal concerns and intentions, the complex relationships between external influences and personal intentions must be considered. Both top-down policy and bottom-up grassroots initiatives can provide guidance and opportunities conducive to ESB. 


\section{References}

Aarts, H. (2007). On the emergence of human goal pursuit: The nonconscious regulation and motivation of goals. Social and Personality Psychology Compass, 1(1), 183-207.

Arnocky, S. \& Stroink, M. L. (2011a). Variation in environmentalism among university students: Majoring in outdoor recreation, parks, and tourism predicts environmental concerns and behaviors. Journal of Environmental Education, 42, 137-151.

Arnocky, S. \& Stroink, M. L. (2011b). Gender differences in environmental concern and cooperation: The mediating role of emotional empathy. Current Research in Social Psychology, 16(9), 1-14.

Arnocky, S., Stroink, M. L., \& Decicco, T. (2007). Self-construal predicts environmental concern, cooperation, and conservation. Journal of Environmental Psychology, 27, 255-264.

Bamberg, S. (2002). Effects of implementation intentions on the actual performance of new environmentally friendly behaviors-results of two field experiments. Journal of Environmental Psychology, 22(4), 399-411.

Bamberg, S., \& Möser, G. (2007). Twenty years after hines, hungerford, and tomera: A new metaanalysis of psycho-social determinants of pro-environmental behaviour. Journal of Environmental Psychology, 27(1), 14-25.

Bargh, J. A. (2006). What have we been priming all these years? On the development, mechanisms, and ecology of nonconscious social behavior. European Journal of Social Psychology, 36(2), $147-168$.

Clayton, S., \& Brook, A. (2005). Can psychology help save the world? A model for conservation psychology. Analyses of Social Issues and Public Policy (ASAP), 5(1), 87-102.

Connolly, J., \& Prothero, A. (2008). Green consumption: Life-politics, risk and contradictions. Journal of Consumer Culture, 8(1), 117-145.

Dupuis, D. R., Shantz, E., \& Bergen, A. (2011). Report to transition Guelph: Feedback on the Resilience 2011 Awareness and Engagement Campaign. The Research Shop, Institute for Community Engaged Scholarship (ICES), University of Guelph (http://theresearchshop.ca/resources).

Gardner, G. T. \& Stern, P. C. (2008). The short list: The most effective actions U.S. households can take to curb climate change. Environment, 50(5), 12-24.

Kaplan, S. (2000). Human nature and environmentally responsible behavior. Journal of Social Issues, 56(3), 491-508.

Kazdin, A. E. (2009). Psychological science's contributions to a sustainable environment: Extending our reach to a grand challenge of society. American Psychologist, 64(5), 339-356.

Leiserowitz, A. (2007). Communicating the risks of global warming: American risk perceptions, affective images, and interpretive communities. In S. C. Moser \& L. Dilling (Eds.), Creating a climate for change: Communicating climate change and facilitating social change (pp. 44-63). New York: Cambridge University Press.

Liu, J. H., \& Sibley, C. G. (this issue). Hope for the future? Understanding self-sacrifice among young citizens of the world in the face of global warming. Analyses of Social Issues and Public Policy. Advance online publication. doi: 10.1111/j.1530-2415.2011.01275.x

Maiteny, P. T. (2002). Mind in the gap: Summary of research exploring "inner" influences on prosustainability learning and behaviour. Environmental Education Research, 8(3), 299-306.

McKenzie-Mohr, D. (2000). Fostering sustainable behavior through community-based social marketing. American Psychologist, 55(5), 531-537.

Moser, S. C., \& Dilling, L. (2007). Introduction. In S. C. Moser \& L. Dilling (Eds.), Creating a climate for change: Communicating climate change and facilitating social change (pp. 1-27). New York: Cambridge University Press.

Smith, A., \& Longhurst, N. (2010). Grassroots innovations for sustainable development: A new research agenda. Economic Sociology: The European Electronic Newsletter, 12(1), 67-71.

Stern, P. C. (2000). Toward a coherent theory of environmentally significant behavior. Journal of Social Issues, 56(3), 407-424.

Swim, J. K., Clayton, S., Doherty, T., Gifford, R., Howard, G., Reser, J., Stern, P., \& Weber, E. (2010). Psychology and global climate change: Addressing a multi-faceted phenomenon and 
set of challenges. A Report by the American Psychological Association's Task Force on the Interface between Psychology and Global Climate Change (Retrieved February 28, 2011, from http://www.apa.org/science/about/publications/climate-change.aspx).

Tang, T., Karhu, K., \& Hämäläinen (2011). Community Innovation in Sustainable Development: A Cross Case Study. World Academy of Science, Engineering and Technology, 73, 396-403.

DARCY R. DUPUIS is a doctoral student in Applied Social Psychology at the University of Guelph. He conducts basic and applied research concerning psychological factors that affect environmentally significant behaviors. His other research interests include immigration and intergroup relations, and the physical environment's nonconscious effects on thought and behavior.

STEVEN ARNOCKY is an assistant professor in the Department of Psychology at Nipissing University. His research focuses on understanding the human psychological factors that affect environmental degradation. His research interests include how cognitive processes/biases, emotion, and motivations influence consumption practices, fertility-related intentions/behaviors, and environmental conservation efforts. 
Copyright of Analyses of Social Issues \& Public Policy is the property of Wiley-Blackwell and its content may not be copied or emailed to multiple sites or posted to a listserv without the copyright holder's express written permission. However, users may print, download, or email articles for individual use. 